\title{
Queer Densities in Garth Greenwell's What Belongs to You: Narrative, Memory, Corporeality
}

\begin{abstract}
:
Much contemporary queer US literature aims at physical and metaphorical density to write against the systematic subjugation and marginalization of queer lives, the lingering inequalities of LGBTQIA+ people, and the disintegration of alternative spaces and networks. In response to the fragility of safe queer environments in US culture, novels such as Garth Greenwell's What Belongs to You (2016) display density, materiality and compaction. Texts like this utilize and deploy condensed narrative forms, thickening depictions of personal and cultural memory, as well as a material attention to the body. This article moves away from the dominant mode of temporality that has defined queer studies for some time to think more particularly about memory and its relation to narrative and corporeality. By concentrating on Greenwell's novel, this article will show how personal memories of emerging gay subjectivities are entwined in broader queer cultural memories.
\end{abstract}

\section{Keywords:}

cultural memory; Garth Greenwell; US South; corporeality; queer studies; HIV/AIDS 


\section{Introduction}

Hanya Yanagihara's 2015 novel A Little Life is deceptive in its title: at 736 pages, there is nothing little about this expansive queer text. It is a dense and heavy novel; weighty in the reader's hands, ${ }^{1}$ affective, I would argue, in the mind and body. Following four young menJude, JB, Willem and Malcolm - as they make their way through twenty-first-century New York, Yanagihara's novel is mainly a slice of Jude's life, a meditation focused on the fullness of his body, his past, his memories and his desires. As the novel progresses, the weight of Jude's history bears down even more, as we witness his body becoming frailer and more precarious, and learn of the numerous and devastating traumas that defined his childhood and adult life. In some ways, by the end of the novel, we have only learned a little of Jude's life, but the substance and gravity of that psychic and corporeal world still feels solid on the page. I will briefly address Yanagihara's novel below, but put simply, this article tracks the significances of queer density, a term I coin to describe the weight of queer existence being registered by both voluminous and compact contemporary novels from the United States. This article focuses principally on Garth Greenwell's What Belongs to You (2016), offering a textual reading of the novel to show the ways that it vitalizes density in a number of ways: narrative, memory, and corporeality.

I utilize the word "density" for its plural meanings and inferences: quantity, thickness, abundance, compactness, as well as opacity and unknowing. Density, thus, is a metaphor for a range of queer matter, a kind of "weak theory" that, in Heather Love's words, "stays local": "instead of powerful reductions, it prefers acts of noticing, being affected" (2010, pp. 236-7). Borrowing Eve Sedgwick's term, Love points to the ways that a weak theory of "attentiveness" over a strong theory of "hypervigilance" (to whatever we are studying) corresponds more accurately to objects of queer study. I am not proposing queer density as a totalizing way of understanding contemporary queer fiction from the United States, but as a mode of attending to some of the ways in which queer lives are rendered substantial and fleshed-out, as opposed to thin and lifeless (as is so often the case when queer characters are inserted into normative mainstream culture). Queer densities - in terms of narrative, memory and corporeality — are best tracked affectively and subjectively, from moments of close

\footnotetext{
${ }^{1}$ Even if the novel is consumed on an e-reader, I would argue that the substance of the book-its length, its subject matter - is still notably dense, in metaphoric and literal ways.
} 
reading and cultural analysis, from $m y$ perspective on the texts I am examining. As such, density opens up questions of queer life in all its thickness and substantiality.

Put in more political (politicized) terms, the article argues that contemporary queer US literature aims at substantiation and density, writing against the systematic subjugation and marginalization of queer lives, the lingering inequalities of LGBTQIA+ people, and the disintegration and overriding of alternative spaces and networks. Aligning with the theme of this special issue, my sense of queer life here responds directly to the historical context of the twenty-first century, and in particular the Obama and Trump presidencies: from the incarceration and ultimate commutation of Chelsea Manning; to the legalization of same-sex marriage, after Obergefell v Hodges (2015); to the ban on transgender people in the US military; to the co-founding of Black Lives Matter by queer women of color; to the mass shooting at Pulse in Orlando, and so on. This small summary of the moment in which contemporary authors are writing enables us to see the very material obstacles against, and proliferations of, queer livability. In response, then, to the fragility, alteration and absence of safe queer environments in US culture (and elsewhere, of course), novels such as A Little Life and What Belongs to You represent and embody forms of materiality and density. Numerous other texts fit this remit, too, including Justin Torres' We the Animals (2011), Megan Bradbury's Everyone is Watching (2016), and Tim Murphy's Christodora (2016). These texts, regardless of their differences, utilize condensed narrative forms (across various scales, from the novella to the epic novel), thickening depictions and workings-through of memory, and a material attention to the body, especially in relation to race, dis/ability, sexuality, gender, class, and nationality. Density as metaphor works multiply.

After considering a little further the narrative form of A Little Life - as a way to frame my thinking about What Belongs to You - I turn my attention to the (slight) role that memory has played in queer studies, and then consider Greenwell's novel as exemplary of queer density. I suggest that orienting the field toward temporality and memory (rather than simply the former) opens up a multitude of ways to see the past and its workings in the present. The article shows how the form of What Belongs to You - a slim novel, narratively compactboth represents and materializes the heft of memory and the sexual body. Through three sections, the novel charts the relationship between a first-person narrator, an unnamed American living in Sofia, Bulgaria, and Mitko, a local man that he meets in public toilets. The first part follows their blossoming sexual relationship through tentative interactions and social spaces; the second interrupts the narrative and takes us back to the narrator's childhood in the US South, through a forty-two-page-long paragraph; and the final section weaves past 
and present with a longer cultural memory of queerness and the body: the AIDS crisis. Greenwell's novel thus links together personal memories of childhood shame and loss, with broader cultural memories of illness, isolation and sexuality.

To frame more precisely the interest of this article, I want to turn to a consideration of Yanagihara's novel by Greenwell himself. Calling A Little Life the "Great Gay Novel," Greenwell identifies the book's avoidance of "familiar narratives of gay fiction" by portraying complex sexual relationships and shifting identity categories (2015, online). Yet at the heart of the book is Jude and his "queer suffering." The book, Greenwell notes, "slowly discloses luridly gothic episodes from [Jude's] life before college, among them abandonment, ... horrifying physical and sexual abuse, prostitution, and abduction.” Jude's life, Greenwell argues, "is an extreme iteration of the abandonment, exploitation, and abuse that remain endemic in the experience of queer young people" (2015, online). For instance, early in the novel, we learn that Jude has discomfort in his legs and has trouble walking without a cane: his friends "would see him in all sorts of pain, big pains and little ones, would see him wince at small hurts and occasionally, when the discomfort was too profound, would see him vomit, or pleat to the ground, or simply blank out and become sensate" (Yanagihara, 2015, p. 20). The layering of clauses here - and the repetitions of words and consonantal soundsevidences a kind a linguistic and formal density that mirrors the attention to a fleshy corporeality that is also substantive. We will see a similar stylistic tendency in Greenwell's novel.

Tracking Jude's pain further, the novel continuously draws us back to his self-harm, especially his organized and regimented cutting. Through free-indirect discourse, we learn how Jude "had a vision in which he carved away at himself - first arms, then legs, then chest and neck and face - until he was only bones" (Yanagihara, 2015, p. 192), a description that goes on through thickening details. When we reach the truly "gothic episodes" that Greenwell notes, the prose becomes even denser, the sentences unfolding deep into physical and psychic trauma. Thus, part of the novel's physical density relates to the memories and histories of Jude, which are slowly revealed to the people around him (and the reader). But the queer aesthetic of the book, too, Greenwell notes - the gothic, the melodramatic and sentimental tendencies - also produces a thickness of affect. "Part of this is due," Greenwell writes, to the novel's structural conceit: "In nearly every section, a present-moment scene is interrupted for dozens of pages by elaborate flashbacks, mimicking the way Jude's past irrupts into his present" (2015, online). One section of the novel, for instance, reveals Jude's 
reflections on memory, especially those abusive episodes that scar him, literally and figuratively:

There were two ways of forgetting. For many years, he had envisioned (unimaginatively) a vault, and at the end of the day, he would gather the images and sequences and words that he didn't want to think about again and open the heavy steel door only enough to hurry them inside, closing it quickly and tightly. But this method wasn't effective: the memories seeped out anyway. The important thing, he came to realize, was to eliminate them, not just to store them (Yanagihara, 2015, p. 380).

Of course, as the novel goes on, even Jude cannot eliminate the memories of his childhood and adolescence. The image of a vault crammed with memories of queer trauma-rendered thickly through Yanagihara's prose-is a dense figuration of the past that cannot be contained in the past.

In a way similar to What Belongs to You, the narrative form of Yanagihara's novel materializes the memories of its characters, which are in turn deeply connected to the body. In this light, I join Rami Fawaz and Shanté Paradigm Smalls who, in their special issue of $G L Q$ (2018), argue for "the importance of literary form to the specificities of nonnormative or queer sexualities and genders." More precisely, they write, "the actual formal composition of a given text [is] an indicator of varied material histories of sexuality": form "can be understood as a kind of evidence of how queerness is being lived and inhabited by different kinds of LGBTQ people" (Fawaz and Smalls, 2018, p. 179). Queer density is thus a way of thinking, through the metaphorics of form and substance, "that gropes from a haptic space in the middle of things." As Kathleen Stewart says of her own weak theory, the idea is not to get the object of study "right," but to wonder "where [it] might go and what potential modes of knowing, relating, and attending to things" exist already in the object, "as a potential or resonance" (2008, p. 73). Following density through queer fiction-in a range of manifestations - this article reflexively attends to the ways in which writers and texts materialize queer life in all of its fullness. As Fawaz and Smalls write, it is important to turn to queer literary texts (those about queer lives) to see the "specificity of varied experiences of LGBTQ life ... to give texture to, foment debate about, and encourage generous exchanges about what constitutes community, collectivity, and alliance" (2018, p. 177). I would add that these queer texts need not be written by queer authors, but merely be attentive to queer lives and modes of narrating them that do not hinder queer flourishing. Positioned against the 
subjugation of LGBTQIA+ people by heteronormative society, dense queer fiction traverses the body and memory through formal compaction. It is to recollections of queer pasts that I now turn.

\section{Queer time and memory}

While memory studies has expanded from the 1970s onwards, especially in the twenty-firstcentury, queer conceptions of remembrance in this field have remained lacking. ${ }^{2}$ A recent volume such as Memory Unbound: Tracing the Dynamics of Memory Studies (2016) for instance, lacks any sustained engagement with queer history and memory, even though the editors see memory as a "fluid and flexible affair" (Bond, Craps and Vermeulen, p. 1), which clearly utilizes what might be called a queer lexis. Memory studies today explores the multiple ways in which remembrance moves and travels, is mediated and shaped, and its transmitted and altered. ${ }^{3}$ Far from static and lingering only in individuals or objects or collectives, memory is shifting and dynamic. Thus, this article will attempt to bring into contact the discourses of memory studies and queer studies. Concomitantly, queer studies has often considered time and temporality more than memory; I am thinking particularly of Jack Halberstam's In a Queer Time and Place (2005), addressed more fully below, as well as Elizabeth Freeman's Time Binds (2010), the GLQ roundtable discussion “Theorizing Queer Temporalities" (2007), and more recently Lisa Baraitser's Enduring Time (2017). All of these works - and many others besides — address how time and temporality have often been thought and conceived heteronormatively, tied to notions of teleology, linearity and reproducibility. This is vital work to help understand queer orientations and worlds in relation to time. But, while memory and time are closely related, the two are evidently not synonymous. In this article, I want to think less about queer time and more about queer memory because the latter reveals how the past comes to matter in the present, moving towards various futures. That is, time might be a description of the then and now or what is to come, whereas memory is a sense of how the then comes to matter in the now.

\footnotetext{
${ }^{2}$ For an extended elaboration of this critique, see: Clark, Queer Transcultural Memory: US Culture and the Global Context (2018).

${ }^{3}$ In addition to Memory Unbound, see, for instance, Erll and Nünning (ed.), A Companion to Cultural Memory Studies (2010), Assmann and Conrad (ed.), Memory in a Global Age (2010); Hoskins, Digital Memory Studies: Media Pasts in Transition (2018).
} 
Laura Doan's recent article “Queer History/Queer Memory” (2017) attempts to think methodologically about approaches to the queer past, by memory and history scholars. Setting up a tension between these disciplinary models, Doan suggests that a focus on "collective memory" - that is, "the social phenomenon or cultural dimension of what groups remember" (Doan, 2017, p. 114) —helps to think through the history/memory bind. However, memory studies today has moved far past the work of Pierre Nora and Maurice Halbwachs in the twentieth-century that she cites; indeed, memory studies has seen a "departure from orthodox models of memory practice and theory, which have frequently located memory as the geographically and culturally bounded property of particular collectives" (Bond, Craps, and Vermeulen, 2016, p. 3). Indeed, Doan's conception of memory hinges only on the collective dimension rather than its more open cultural form, which accounts for the various ways in which memory is always mediated by texts, objects, people, narrativizations, History and so on. The lack of citations from memory studies as it stands today presents a skewed picture of the field. Memory studies alerts us to the variegated processes of memory: remembrance, forgetting, displacement, amnesia, nostalgia. Such a methodology can track the ways that things get remembered, or do not, as well as illuminate how things come to be remembered in the first place. In that way, memory bridges the personal and collective, the individual and the cultural. The novel has, of course, been the province of subjective personal memories for a long time; in the queer canon, Marcel Proust's $A$ la recherche du temps perdu (1913-1927) stands out as a particularly notable example. Yet "memory," rather than "temporality," can articulate the broader ways in which we remember events as cultures and societies. As such, memory is more elastic, expansive, and flexible (that is, queer) than temporality to account for the ways that the past is understood in the present. Bringing queer and memory together is important if we are to understand contemporary queer life and its histories.

Marita Sturken's Tangled Memories (1998) is still a pertinent example of scholarship that, while not under the mantle of queer studies, addresses cultural memories of AIDSalongside the Vietnam War - in the United States. For her, "Cultural memory is a field of cultural negotiation through which different stories vie for a place in history" $(1998, \mathrm{p} .1)$. Sturken's argument is that far from being a nation of amnesia, the United States is actually saturated with memory cultures. To work through this "tangle" of memory forms, she writes that "We need to ask not whether a memory is true but rather what its telling reveals about how the past affects the present" (Sturken, 1998, p. 2). In other words, memory matters principally in what it tells us about the present: how the past is used, recontextualized, and 
mediated for current needs, fantasies and narratives. Sturken is interested most in how cultural memories, of the AIDS crisis and the Vietnam War, reveal "the stakes held by individuals and institutions in attributing meaning to the past" $(1998$, p. 9). The notions of memory I work with in this article extend from Sturken's argument: I will explore how Greenwell's novel speaks to the particular queer contexts of the twenty-first century. Moreover, I will think about this broader cultural memory-work alongside the more personal memories of the nameless protagonist. This article thus thinks about queer memory and temporality as they are shaped by narrative.

To push further the link between queer memory and time, then, I turn to Halberstam's In a Queer Time and Place which, while firmly a book about temporality can be helpfully enlaced with questions of cultural memory. Halberstam posits that "Queer uses of time and space develop, at least in part, in opposition to the institutions of family, heterosexuality, and reproduction" (2005, p. 1). Queer time, in this formulation, is non-normative, and defined against heteronormativity. Queerness, as "an outcome of strange temporalities" $(2005$, p. 2), is thus less about sexual and gendered identities than ontological habitations. Queer lives, for Halberstam, are (in short) marked by temporalities and spaces that are non-normative. A key milestone in queer time, the book suggests, is the AIDS pandemic, which ushered in, from the 1980s onwards, a so-called "diminishing future" that "create[d] a new emphasis on the here, the present, the now" (Halberstam, 2005, p. 2). This "urgency of being" (Halberstam, 2005, p. 2) in the present is at once a response to the catastrophe of AIDS and its wiping away of the horizon of futurity for so many queer people (those that died and those that survived), but also a recognition that the present is of importance and value for all. As Lee Edelman has argued in No Future (2004), the present can also be a rejection of the future and the logics of reproductive futurism as configured by heteronormativity. Halberstam, finally, posits that "queer time, even as it emerges from the AIDS crisis, is not only about compression and annihilation; it is also about the potentiality of a life unscripted by the conventions" of heteronormativity $(2005$, p. 2). Running with that term - compressionwhich overlaps with density as another metaphor of materiality and substance, I want to decouple it from death or "annihilation" (as Halberstam notes here) and show its vitalizing potentiality in the present. Queer memory, compressed, is not memory that disappears but memory that is affectively charged and potently dense in the present. Greenwell's novel, as we will see, utilizes formal and thematic constructions of queer memory that is compressed through formal means. 
The narrator says, thinking about Mitko, "Like everything else in my past he was part of the story that had led us to each other; it's a way of being in love, I think, to see the past like that" (Greenwell, 2016, p. 117). Seeing the past like that - understanding everything in the past is interlinked, constitutive of the present - is a form of love, but it is also an echo of memory studies that puts emphasis on seeing the past in a particular way, like that. Susannah Radstone and Bill Schwartz, for instance, suggest that "Memory is active, forging its pasts to serve present interests," and "memory's activities in the present belie the apparently simple, reified, and knowable past evoked by the call to remember" $(2010$, p. 3$)$. Thus, both memory studies and Greenwell's novel shed light on how the past's ostensible fixity is actually malleable, and that history is ever present through its uses, deployments and re-articulations. What Belongs to You, in its movement toward condensation rather than expansion, density over the transitory, keeps memory moving.

\section{Feeling backward}

The novel opens with a moment of intimacy in a public space, a condensation of emotions, and the hint of tragedy; all of this, moreover, is written in Greenwell's characteristically dense prose-style:

That my first encounter with Mitko B. ended in a betrayal, even a minor one, should have given me greater warning at the time, which should in turn have made my desire for him less, if not done away with it completely. But warning, in places like the bathrooms at the National Palace of Culture, where we met, is like some element coterminous with the air, ubiquitous and inescapable, so that it becomes part of those who inhabit it, and thus part and parcel of the desire that draws us there (Greenwell, 2016, p. 3).

Greenwell, through these two unfolding sentences, grounds What Belongs to You in queer recollection. The way Greenwell's sentences layer clause on clause, extending and complicating thought, is one way in which the narrative is formally and linguistically dense. The narrator's cruising in a public toilet beneath the National Palace of Culture-both underscoring the subterranean nature of this "illicit" meeting-place and suggesting the undergirding of social life by queerness - is a moment of reflection on when the narrator met Mitko, as well as a foreshadowing of how their relationship develops. Moreover, by recasting 
"warning" as both a signifier of the future and an affect that structures desire in this space, the narrator points to the symbolic heft of this first meeting.

Mitko is a young man who "claimed" the narrator's "attention" in a "brash" way that was "entirely public in that place of intense privacies" (Greenwell, 2016, p. 4). This language hinges on the public/private dialogue so central to cruising culture, one that highlights the commingling of exposure and secrecy. Lauren Berlant and Michael Warner (1998, p. 558) call this process queer world-making: the creation of "kinds of intimacy that bear no necessary relation to domestic space, to kinship, to the couple form" and so on. The worldmaking that begins in the public toilets opens both Mitko and the narrator to intimate forms of belonging beneath (literally) the normative dominant culture of Sofia. Mitko then agrees to have sex with the narrator for a money. He, "with a bodily candor ... pulled the long tube of his cock free from his jeans and leaned over the bowl of the sink to wash it, skinning it back and wincing at water that only comes out cold" (Greenwell, 2016, p. 4). We see an emphasis on Mitko's body, his fleshy physicality, that continues throughout the novel-it is a book focused on the ways in which corporeality and desire, sex and memory, come together.

Over the first section of the novel, titled "Mitko," the men have sex several times, but Mitko requests money from the narrator, accentuating the perhaps provisional but always transactional nature of their connection. This part is told, as in the rest of the novel, through the narrator's tendency “toward confession” (Greenwell, 2016, p. 11). Such a confessional mode — which is as revealing as it is obscuring (we never find out the narrator's name ${ }^{4}$ ) - is one of density, of narratorial and linguistic thickness. Describing a night sleeping with Mitko, the narrator says: "He lay like some marine creature wrapped around me, wrapping around me again if I shifted or half woke, and I slept as I have seldom slept, deeply and almost without disturbance, held like his beloved or his child; or held, I suppose it must be said, like his captive or his prey" (Greenwell, 2016, p. 30). Both formally and thematically through the clauses and the imagery, Greenwell's narrator densely entwines bodies, identities, and the glue between desire and violence. These themes are amplified in part two of the novel, where the narrative turns to the narrator's childhood.

\footnotetext{
${ }^{4}$ Much could be said about how only Mitko is named in this novel. The narrator remains nameless, and other characters are reduced to a mere letter (K., for instance). At one level, this device underlines the role of desire and fantasy at work in the book: the narrator sees only Mitko, in his simplicity and ambiguity, his physicality and unknowability. Yet at another, it connotes the silences, gaps, and absences in the articulation of queer identity in the twenty-first century. The structure of revelation and concealment, too, central to Eve Sedgwick's canonical Epistemology of the Closet (1990), courses through this book's structure and process of un/naming.
} 
Titled "A Grave," the narrator's history is far from dead and buried in part two of the novel. The section begins, self-reflexively, in medias res: "I was in the middle of a sentence when there was a knock at the door" (Greenwell, 2016, p. 61). Interrupting a class that he is teaching is news that the narrator's sick father, back in the United States, wants to see him after numerous estranged years. From this syntactical and narrative interruption-literally piercing the current events of the book - a forty-two-page section, without paragraph breaks, unfolds. Here the novel compresses narrative and memory through an extended block of text that takes us back to the narrator's early relationship with his father. Such formal condensation (no breaks, no pauses) is mirrored by the density of remembrance. Describing his walk home from the school, across the town, the narrator notes things and people that he should have seen, but "I have no memory of them now. I was seeing something else, images that burst in on me, scenes from a childhood I hadn't thought of for years; I had worked hard to forget them but now they came all at once, too quickly to make any sense of them" (Greenwell, 2016, p. 63). Greenwell's prose here not only reveals the thickness of memory, and the way it impinges on the present, almost blocking out things that are happening to the narrator there and then, but it also shows how remembrance and forgetting are ever-active processes, two interconnected ideas.

At the heart of "A Grave" is the narrator's overwhelming past in the US South, one marked by rejection, shame, and alienation, as he comes to terms with his own sexuality, and his father's discovery that his son is gay. This part of the book epitomizes what Heather Love calls "feeling backward": that tendency in late nineteenth and early twentieth-century literature toward a past "visibly marked by queer suffering" (2009, p. 4). Alexandra Parsons similarly notes this turn in both Greenwell and Yanagihara's novels: "their characters experience shame and loneliness, caused by irreparable wounds in their pasts" (2019, p. 142). Such dark affects turn on an "account of the corporeal and psychic costs of homophobia," and as such run toward feelings of "nostalgia, regret, shame, despair," among others (Love, 2009 , p. 4). Feeling backward, ultimately, is "tied to the experience of social exclusion and to the historical 'impossibility' of same-sex desire” (Love, 2009, p. 4). While that "impossibility" ostensibly may not seem to have as much currency in the twenty-first century United States, this article's opening suggested the manifold ways that queer lives and queer desire are still being curtailed today. Thus, queer love (as evidenced by Greenwell's novel) is still shadowed by suffering.

What might be called the novel's queer primal scene occurs when, as a young boy, the narrator spends time with his father, after he separates from the narrator's mother. The 
"closeness" they share at first_- "access to his physical presence without suspicion or doubt" - transforms, as he ages, into feelings of "greater solemnity and unease," an emotion the narrator also feels around his male friends at school (Greenwell, 2016, p. 71). The narrator remembers showering with his father, enjoying an intimacy whereby they would wash each other's backs: in this act, "he was gentle," where usually his father was "severe and sometimes cruel" (Greenwell, 2016, p. 72). On this particular occasion, the narrator remembers:

I approached him, not with any specific intent but perhaps not innocently either, I can't be sure after so many years .... Or maybe it's more true to say I was innocent but not without intent ... I wanted to touch him, not with an outcome in mind but with an ache ..., which drove me to him and which he felt, too, when I put my arms around him and pressed my body to his and he felt my erection where it touched him (Greenwell, 2016, p. 72).

The concentration of these lines - embedded in an already dense section — echo the confusion and confliction of the narrator. As he tries to pinpoint his reasons or intentions for approaching his father, aroused, the sentences become more contorted, looping and replicating words. The memory itself shifts as it is retold. The outcome of this corporeal gesture ushers in "the end of care" from his father; he pushes the narrator away, and his face is "twisted with disgust": "his true face, his authentic face" (Greenwell, 2016, p. 72). It is as if this moment of conflicted needs and desires reveals the father's real feelings towards his son: the mask of paternal care slips to show the disgust underneath. Of course, this is partly the narrator's retrospective coding of his father; a feeling backwards of shame, loss, and selfabrogation. And if children, and childhood itself, is always already queer - as Kathryn Bond Stockton argues (2009) - then these key developmental touchstones are also shot through with layers of non-normativity and estrangement.

Yet, the backwardness of this scene can also seen in its deployment of pederasty, a classically historical queer trope of homosexual desire. Kadji Amin, in Disturbing Attachments (2017), argues that this "age-structured male same-sex form" has been "undertheorized" in queer studies, in part because of its "inegalitarianism - its impolite and impolitic admission that it gets off on power," especially between "an adult and a minor" (p. 10). Even though it is a "putatively nonmodern and not-yet-liberated practice," and thus "associated with internalized homophobia, social violence, and sexual exploitation," Amin 
tracks the ways that pederasty's connections to backwardness and "the retrograde" can "foreground and trouble contemporary queer orientations toward novelty and futurity" (2017, p. 32, p. 29). In this novel, dense with queer memory, such a turn back to a moment of “disturbing" sexual desire between an adult and a child (a father and a son) highlights yet another way that the past and the present enfold. Yet, rather than the usual script of an older sexual aggressor taking advantage of a minor, here the child is the one that moves sexually toward that adult: reversing the pederastic script queerly. While the father's toxic masculinity materializes in a form of gay panic — his face "twisted with disgust" - this primal scene inverts the "nonegalitarian, nonreciprocal sexualization of social hierarchy" to query desire's queer movements (Amin, 2017, p. 37). The scene is dense, formally and thematically, with the complications of queer desire.

Mirroring this scene of troubled eroticism is the narrator's close relationship to his friend K. After a day of being outside, they return in the evening to the narrator's house. As the night goes on, the narrator gives $\mathrm{K}$. a back massage, ending with him sensually wrapped around his friend. When they wake, K. is immediately ill: "I could see that he had vomited and now he vomited again" (Greenwell, 2016, p. 81). Though the narrator thinks this sickness must relate to something the boys ate, read psychoanalytically it testifies to the expulsion or rejection of something complexly internal. As theorists from Sigmund Freud to Melanie Klein and beyond argue, vomit is one bodily symptom, among many, that signal internal conflict in a physical form. As Freud notes in "The Psychotherapy of Hysteria" (1895), the impulse to vomit (especially in therapy) is often a hysterical symptom: a materialization or manifestation of an unconscious process that one cannot face or access. K. attempts to rid himself, psychosomatically and thus unconsciously, of a feeling or affect through physical means. The narrator has his father drive K. home, but on the way, the range of emotions that have been unearthed in K. close him off from the narrator. He will not look at him, and only answers the narrator's father. "I felt him turn from me," the narrator says, and "in that foul air I felt him identify me as foulness. It was as though he felt my father was health and I contagion" (Greenwell, 2016, p. 84). I will think further about sickness and contagion below - in relation to the third section of the novel—but here it seems that $\mathrm{K}$. has disavowed the homoerotic connection with the narrator by throwing it up, casting out that which is queerly abject. For Julia Kristeva (1982, pp. 1-2), the abject, like many objects, is that which is "opposed" to the self; but rather than inciting or sustaining desire, the abject is a "jettisoned object," "radically excluded and draws me toward the place where meaning collapses." Like queerness, abjection "disturbs identity, system, order," and it ignores "borders, positions, 
rules" (Kristeva, 1982, p. 4). The father, representing heteronormativity and masculinity, is a figure to identify with, where the narrator is that queer other to be rejected and cast out.

This event draws the two boys apart for some time, but K. eventually calls the narrator back into his life once he has a girlfriend. Unable to do anything sexual with this girl-K.'s mother will not allow them alone in a room together-K. asks the narrator over, so that he can be present in the bedroom too. The narrator becomes a safe way for $\mathrm{K}$. and his girlfriend to be sexual with one another, without causing suspicion in his mother. The scene culminates in the narrator awkwardly sitting in the corner of the room as K. and his girlfriend have sex, but K. "knew I was watching and he let me watch. It was like a parting gift" (Greenwell, 2016, p. 90). This gift, of entangled desires between the boys, is reflected upon by the adult narrator: "I've sought it ever since, I think, the combination of exclusion and desire I felt in his room, beneath the pain of exclusion the satisfaction of desire" (Greenwell, 2016, p. 90). Pinpointing here the way in which this queer childhood - and its attendant affects, desires, and structures of feeling - shape and live on in the present, this memory sheds light on the power dynamics between the narrator and Mitko, for example.

The third and final key moment in this section of childhood memories occurs when the narrator is locked out of the house by his step-mother after a fight. What eventually transpires is his parents' knowledge of his feelings for K.: "they had found ... a notebook in my room" (Greenwell, 2016, p. 98). This book, containing his queer desires, acts as a catalyst for the family's detonation and the narrator's father lashes out: "A faggot, he said, if I had known you would never have been born .... As I listened to him say these things it was as though even as I laid claim to myself I found there was nothing to claim, nothing or next to nothing, as though I was dissolving and my tears were the outward sign of that dissolution" (Greenwell, 2016, p. 100). Such a traumatic moment — of the notebook's revelation, the homophobic slur, and the subsequent shattering of selfhood—scars and marks the narrator with hatred and shame. Again, this section is dense with backward feelings surrounding the narrator's queer identity. Indeed, not only revealing the depths of this family's anti-gay feelings, the scene (and the entirety of this section set in rural Kentucky) perhaps conforms to an idea of the US South as especially conservative and homophobic. As Michael Bibler argues, "The stereotype of a queer-phobic South is linked to the long-standing view that the South is the nation's backward and perverse regional Other" (2016, p. 201). In other words, there is an ongoing cultural narrative of the South as housing and containing those parts of the United States that the nation wants to disavow (conservatism, sexism, racism, homophobia and so on). 
The anti-gay South that we see in Greenwell's novel—an inhospitable place for this queer child and adolescent — conforms to dominant cultural ideas about the region. Yet, as Donna Jo Smith writes, "Since the South is already an aberration, what is a southern queer but deviance multiplied?" (1997, p. 381). Put this way, the South is inherently queer and Other, thus the narrator's childhood is part of a broader sense of regional and personal subjugation. The density of this memory, then, not only details the formation of the narrator's psychic and somatic life, but also his grounding in the abject space of the South. Previous southern literature, Bibler writes, has detailed the "opening up, rather than condemning, the push and pull between deviance and normalcy" (2013, p. 202), and What Belongs to You perhaps contributes to that dialogue. At once a casting-out from the South - the narrator leaves home and eventually moves to Europe - this dense section of the novel also foregrounds the importance and significance of the narrator's childhood in Kentucky to his queer identity. That the prose condenses and thickens, dissolving into one paragraph, only but materializes or mirrors the compaction and affect of such remembrance.

At the end of the section, returning to the present day, the narrator sees a horse on his walk home, a "pitiful creature, sicky and thin, its skin hanging loose over protruding ribs" (Greenwell, 2016, p. 101), a description that gestures forward to the sickness in the final section of the novel, that begins merely a page later (or, indeed, reflects back on K.'s vomiting). The horse, though "hitched" to a cart, "wasn't tied up" and thus "could have wandered off anytime it chose; but there was nowhere for it to go, of course, and the cart I supposed was heavy, and there was something however meager to be had there where it stood" (Greenwell, 2016, p. 102). This brief moment metaphorizes, I suggest, the relationship that the narrator has to his past. While, of course, the narrator leaves the United States for Bulgaria (unlike the horse who does not wander off), he is nonetheless "hitched" to his "heavy" memories. Though they are limiting and traumatic, these memories are "something" that tether him to the past and his emergent gay identity. Feeling backward, like the horse, has a physicality to it, even if it is "sickly."

\section{On sex and disease}

Part three of the novel, like the second, opens self-reflexively on an interruption: "When the knock came, quick and assured, I heard it without surprise" (Greenwell, 2016, p. 105). After some time apart, Mitko returns to the narrator's apartment with news that he has contracted syphilis. Greenwell entangles personal memories of childhood with cultural memories of 
queer history, particularly of the AIDS crisis. Titled "Pox," this section underscores how illness and its perceptions are central to the book's narrative logic. The density of queer bodies, of illness, of community and history, intertwine.

On hearing the news of Mitko's infection, the narrator “draw[s] back without thinking, a reflex against contagion and against the word, too, feeling horror at a nineteenthcentury disease I only knew about from books, so that my first thought, immediate and vivid, was of Flaubert on his travels" (Greenwell, 2016, p. 108-9). In this typically unspooling (dense) sentence, Greenwell articulates a number of things. Firstly, we see how the narrator unconsciously treats the infection as something abject, to recoil from. As we saw above, the abject is that which is both other to the self, and which undoes identity and its boundaries. Greenwell traces a line from the childhood memory of vomit and expulsion to this revelation of sexual disease. Secondly, illness is then consigned both to the past- "a nineteenth century illness"- and to a literary realm — the "word" itself, and its associations with Flaubert. Syphilis, for the narrator, exists as something locked into the past.

Yet, the "horror" of the "contagion" reveals how the disease functions as a cultural idea. For, as Priscilla Wald tells us, "Microbes tell the often hidden story of who has been where and when, and of what they did there. Contagion ... charts social interactions that are often not otherwise visible" (2008, p. 37). Wald here points to the communal and social dynamic of infections - the way that contagions and viral networks expose people, acts, and spaces that have otherwise been private and unseen. As Susan Sontag puts it in Illness as Metaphor (1978), "there was horror aplenty in syphilis. But no mystery. Its causality was clear" (p. 61). Mitko's syphilis discloses not only his various sexual relationships outside of the narrator, but also exposes the narrator's position in that chain of bodies; indeed, his own boyfriend will now have to be told about the infection. We might think about this queer chain of people alongside Tim Dean's notion, in Unlimited Intimacy (2009, p. 78) that bareback sex, and the transmission (or "gift-giving") of HIV, "allows men to bond with each other," through "materializing a sense of brotherhood" or queer kinship. Though syphilis is not HIV or AIDS - as I will explore further below - the associative links between the two are clear. While we do not know if the characters have bareback sex, it is notable that condoms are conspicuously absent from the narrative itself. Drawing together a community of men who 
have had sexual encounters, Mitko's revelation reveals a queer web, a dense and physical network of people in Sofia. ${ }^{5}$

The narrator's reflex against the news is misrecognized by Mitko, who thinks that the narrator is disbelieving rather than disgusted. As such, Mitko pulls down his trousers and takes out his penis. Eliciting feelings of "eagerness" and "amaze[ment]" in the narrator, who is taken aback by Mitko's comfort in being naked, and by the physicality of the penis, the act culminates in Mitko drawing a "single drop" of "cloudy and white" fluid from the organ's tip. Echoing, for the narrator, sexual acts between them, the discharge is "indistinguishable from semen, really," which, in turn, produces what Freud might call an uncanny sensation: "maybe it was the very similarity that so repulsed me" (Greenwell, 2016, p. 109). The simultaneous familiarity and unfamiliarity of the bodily substance evokes a reaction that estranges the narrator. Such entwining of sexual pleasure and sexual infection is part of the corporeal queer density I'm tracking here.

Days later, the narrator is drawn erotically back to Mitko and ends up having a sexual encounter with him in a McDonald's toilets. Afterwards, feeling the usual "regret" (p. 134) following such contact, the narrator also feels panicked and shamed because other people, including children, use the restaurant's facilities. Here, the (queer) public sex evokes not only personal feelings of remorse in the narrator, but it also raises the specter of the "innocent" child who may be tainted and corrupted not only by sexuality, but sexuality in its queerest form. Even though we have noted that children, in Bond Stockton's argument, are already queer, the imaginary of the "pure" child-to-be-protected indexes the threat of homosexuality that the narrator has internalized as shame. He "began wiping down the porcelain [of the toilet] itself, inside and out. I know the whole performance was excessive, I was wiping surfaces unlikely ever to be touched" (Greenwell, 2016, p. 134). The sense of contagion again here takes over, but so too does a sense of guilt about such a sexual act (and a bodily exposure) in this public space. Elsewhere in this section, the narrator uses words such as "pollution" and "unclean" and "contaminate" (pp. 109, 127) to refer to Mitko and syphilis, underscoring that even with an awareness of the disease's treatability, he still feels the cultural weight (density) of its associations.

This extended dialogue with the narrator's, and Mitko's, syphilis is a coded way of confronting the AIDS crisis and its aftermath. In this way, Greenwell's novel is continuing an

\footnotetext{
${ }^{5}$ At the "Queer Subjectivities in the United States" conference, on which this special issue is based, the keynote, Sam McBean theorized a methodology and aesthetic framework for conceiving queer networks, especially in digital media.
} 
historical trajectory that Sturken notes occurred in the 1980s. As the crisis unfolded, people with AIDS "were represented as a figure of disease whose meanings bore the legacy of centuries of disease representation." Specifically, “infected people have often been depicted as vessels containing a disease, as extensions of it" (Sturken, 1998, p. 148). Thus, those with AIDS bore the symbolic and cultural weight of other infections and illnesses, like syphilis. ${ }^{6}$ Indeed, Sturken argues, as "syphilis carried with it the stigma of moral deviancy" because of its relationship to "sexual contact," so too did the AIDS crisis. Yet AIDS also wore "the image of a plague, a scourge upon an entire community" (1998, p. 148). The narrator of What Belongs to You, at one moment, acknowledges this associative link: "I grew up at the height of the AIDS panic, where desire and disease seemed essentially bound together, the relationship between them not something that could be managed but absolute and unchangeable, a consequence and its cause" (Greenwell, 2016, p. 122). This sentence glues sex and illness, desire and risk, the individual and the nation, together in a complex assemblage.

As with HIV and AIDS, echoes of blame and the absence of treatment also appear in the novel. An extended portion of the narrative involves the narrator having to traverse Sofia to reach a medical center on the outskirts of the city to obtain treatment. When he is finally seen, a nurse reveals that "there is no penicillin available" (Greenwell, 2016, p. 148) anywhere in Bulgaria, and this has been the case for a number of months. Not only does this revelation undercut Mitko's story - he tells the narrator that he used the money given to him to get antibiotic shots - but it reveals a medicine shortage that arguably is deployed to evoke memories of the AIDS pandemic. Moreover, as the nurse gives the narrator a course of pills, instead of injections, she asks accusingly, "did you have this disease when you came here, did you bring it with you?" (Greenwell, 2016, p. 150). Blaming the narrator functions as a way to expunge the disease from the national body politic, locating it in the United States (due to the nationality of the narrator) or in a broader queer community outside of the heteronormative sphere. The geographical site of the medical center, on the city's outskirts, reinforces the way that (some) sexual disease is marginalized and cast out.

In focusing so clearly on Mitko's infection, the narrator's perception of it, and the context for receiving medical treatment, Greenwell simultaneously calls up cultural memories of AIDS and keeps them at bay. The chain of associations means that Mitko's syphilis is shadowed by AIDS, but not rendered deathly. In the cultural imagination AIDS and HIV

\footnotetext{
${ }^{6}$ Susan Sontag tracks a number of these connections in AIDS and Its Metaphors (1989).
} 
were (and still are) frequently tethered to death; thus, the treatability of the syphilis through medication stands in contrast to the debilitations of AIDS, which leads to complications and other illnesses. Yet, we need also acknowledge that syphilis and other STIs are illnesses which are once again on the rise because of treatments like PrEP (Pre-Exposure Prophylaxis), which "threatens to supersede the low-tech prophylaxis of condoms" (Dean, 2015, p. 228). In the current era of PrEP, condomless sex (barebacking) is becoming more of a sexual norm, though Greenwell's novel does not mention such treatment. In fact, given the difficulty the narrator has getting medication to treat the syphilis, it would be surprising if the characters were indeed taking PrEP. As such, both the past and present of queer sex(uality) is simultaneously evoked and ignored, disavowed at the level of form and content.

Put starkly, I am arguing that Greenwell's novel processes memories of the AIDS crisis and its aftermath without confronting the complexity, trauma and depth of that pandemic. Sturken writes, "The politics of remembering AIDS can never be detached from the fact that the epidemic is still killing people" (p. 176); this statement, though written in 1998, still has much relevance in the twenty-first century, even in the United States. Such open-endedness means that, for Sturken, "Cultural memory in the context of AIDS is not about achieving closure but about keeping any sense of closure at bay" (1998, p. 176). Memory is an ever-active process, hinging on both remembering and forgetting; Sturken argues that AIDS' unfolding in the present means that its memories will not die. Thus, adding to Monica B. Pearl's contention that the "grief, mourning, and letting go" found in much queer literature before AIDS (but after Stonewall) "constituted the gay community" to some degree (2013, p. 8), Greenwell's novel does not so much mourn and let go of the losses of AIDS, but keeps them proximate. In other words, a gay or queer community is re-reaffirmed by invoking this shared memory and history. Existing in the wake of HIV and AIDS memories - the materiality of that past, its impact on the present, and the way illness is felt in and on the body-What Belongs to You offers a queer density that is multifaceted and not simply recuperative.

\section{Conclusion}

Writing against the systematic subjugation of queer peoples in the United States, contemporary fictions of queer density are not idealistic or unproblematic. But they do formalize and give substance to subjectivities that are often denied agency, visibility, representation or voice in wider culture. Recalling Yanagihara's novel that framed this 
article, we might argue that, like $A$ Little Life's notable silence about HIV and AIDSstriking because of the novel's explicit invocation of disease, illness, and trauma in relation to queer men in New York City_Greenwell's novel enacts a kind of cultural forgetting or amnesia. Yet, I would suggest that in both cases, the density of the books (in form, in narrative, in memory, in corporeality) substantiate a range of queer histories and subjectivities that keep cultural memory moving, around queer history. It is the "tangle" of memory, to borrow from Sturken's book title, that is formalized through queer density. And if, as Halberstam writes, queer time is about compression and liberation - both of which are inflected by the past, present, and future - then perhaps the recent swathe of gay US novels about memory are significant to the work of queer studies going forward. Though the example I have explored here is about (white) gay men, the political and aesthetic work of the novel's density sheds much light on contemporary queer subjectivities and pasts. In a precarious national context, queer literature can offer refuge, substance and visibility.

\section{References}

Amin, K. (2017). Disturbing attachments: Genet, modern pederasty, and queer history. Durham, NC: Duke University Press.

Baraitser, L. (2017). Enduring time. London: Bloomsbury.

Berlant, L. \& Warner, M. (1998). Sex in public. Critical Inquiry, 24(2), 547-566.

Bibler, M. P. (2013). Queering the region. In S. Monteith (Ed.), The Cambridge companion to the literature of the American South (pp. 188-203). Cambridge: Cambridge University Press.

Bibler, M. P. (2016). Queer/Quare. In S. Romine \& J. R. Greeson (Eds.), Keywords for Southern Studies (pp. 200-212). Athens: University of Georgia Press.

Bond, L., Craps, S. \& Vermeulen, P. (2016). Introduction: Memory on the move. In L. Bond, S. Craps and P. Vermeulen (Eds.), Memory Unbound: Tracing the dynamics of Memory Studies (pp. 1-26). New York \& Oxford: Berghahn.

Clark, C. W. (2018). Queer Transcultural Memory: US Culture and the Global Context (Unpublished doctoral dissertation). University of East Anglia, Norwich.

Dean, T. (2009). Unlimited intimacy: Reflections on the subculture of barebacking. Chicago: The University of Chicago Press. 
Dean, T. (2015). Mediated intimacies: Raw sex, Truvada, and the biopolitics of chemoprophylaxis. Sexualities, 18(1-2), 224-246.

Dinshaw, C., Edelman, L., Ferguson, R. A., Freccero, C., Freeman, E., Halberstam, J., Jagose, A., Nealon, C., Hoang, N. T. (2007). Theorizing queer temporalities: A roundtable discussion. GLQ: A Journal of Lesbian and Gay Studies, 13(2-3), 177-195.

Doan, L. (2017). Queer history/queer memory: The case of Alan Turing. GLQ: A Journal of Lesbian and Gay Studies, 23(1), 113-136.

Edelman, L. (2004). No future: Queer theory and the death drive. Durham, NC: Duke University Press.

Erll, A. \& Nünning, A. (Eds.) (2010). A companion to cultural memory studies. Berlin: De Gruyter.

Fawaz, R. \& Smalls, S. P. (2018). Queers read this! LGBTQ literature now. GLQ: A Journal of Lesbian and Gay Studies, 24(2-3), 169-187.

Freeman, E. (2010). Time binds: Queer temporalities, queer histories. Durham, NC: Duke University Press.

Freud, S. (2001). The psychotherapy of hysteria. In J. Strachey (Ed.), The standard edition of the complete psychological works of Sigmund Freud, Volume II (1839-1895) [Studies on hysteria. By Josef Brauer and Sigmund Freud] (pp. 253-305). London: Vintage.

Greenwell, G. (2015, May 31). A Little Life: The great gay novel might be here. The Atlantic. Retrieved from https://www.theatlantic.com/entertainment/archive/2015/05/a-littlelife-definitive-gay-novel/394436/

Greenwell, G. (2016). What belongs to you. London: Picador.

Halberstam, J. (2005). In a queer time and place: Transgender bodies, subcultural lives. New York: NYU Press.

Hoskins, A. (Ed.) (2018). Digital memory studies: Media pasts in transition. New York and Abingdon: Routledge.

Kristeva, J. (1982). Powers of horror: An essay on abjection. Trans. by L. S. Roudiez. New York: Columbia University Press.

Love, H. (2009). Feeling backward: Loss and the politics of queer history. Cambridge: Harvard University Press.

Love, H. (2010). Truth and consequences: On paranoid reading and reparative reading. Criticism, 52(2), 235-241. 
Parsons, A. (2019). Queer. In D. O’Gorman \& R. Eaglestone (Eds.), The Routledge Companion to Twenty-First Century Literary Fiction (pp. 136-146). London and New York: Routlegde.

Pearl, M. B. (2013). AIDS literature and gay identity: The literature of loss. London and New York: Routledge.

Sedgwick, E. (1990). Epistemology of the closet. Berkeley and Los Angeles: University of California Press.

Smith, D. J. (1997). Queering the South: Constructions of southern/queer identity. In J. Howard (Ed.), Carryin' on in the lesbian and gay South (pp. 370-386). New York: New York University Press.

Sontag, S. (2002). Illness as Metaphor and AIDS and its metaphors. London: Penguin.

Stewart, K. (2008). Weak theory in an unfinished world. Journal of Folklore Research, 45(1), 71-82.

Stockton, K. B. (2009). The queer child, or growing sideways in the twentieth century. Durham, NC: Duke University Press.

Sturken, M. (1997). Tangled memories: The Vietnam war, the AIDS epidemic, and the Politics of Remembering. Berkley and Los Angeles: University of California Press.

Wald, P. (2008). Contagious: Cultures, carriers, and the outbreak narrative. Durham, NC: Duke University Press.

Yanagihara, H. (2015). A little life. London: Picador. 